\title{
HOSPITAL AIRCRAFT IN THE FIGHT AGAINST THE CORONAVIRUS PANDEMIC: STRUCTURING AND MODELING A COMPLEX PROBLEM USING AHP AND VFT METHODS
}

\begin{abstract}
The COVID-19 pandemic has threatened the capacity of health systems worldwide, with several cities declaring the collapse of the hospital system. In order to find a way to support Brazil in the fight against the pandemic, this paper applied the Analytic Hierarchy Process (AHP) and Value-Focused Thinking (VFT) methods to select the most suitable hospital aircraft to be acquired by the Brazilian government. The airplane would be used in aeromedical evacuations, supporting the fight against the pandemic, especially in cities where there are no more ICU beds available, transporting patients to other locations with greater structure, technological and technical experience. Six models manufactured by Embraer, employed in aeromedical evacuations, were evaluated in the light of operational, technical and commercial criteria. This paper aims to solve a problem of extreme relevance to academia and society, as it contributes to the solution of a problem that affects millions of people in Brazil and worldwide. After the application of the AHP and VFT methods, Legacy 450 aircraft was chosen as the most indicated to be acquired by the Government and used as hospital aircraft in the fight against the pandemic.
\end{abstract}

Keywords: Analytic Hierarchy Process (AHP), Multicriteria analysis, Public healthcare, COVID-19.

\section{Introduction}

The new coronavirus has highlighted a number of weaknesses in the world's health systems, emphasizing the problems in accessing the essential resources needed to address this pandemic, such as lack of respirators and protective equipment. One of the most serious problems for health authorities in countries that have a considerable increase in the number of cases in COVID-19 is the collapse of the hospital system (Gutiérrez-Aguilar et al., 2020).

Given the extremely serious situation in Brazil, this paper aims to propose available solution to support the fight against the pandemic, taking into account mainly the lack of beds in some cities in the country and the operational inequality (different availability of beds, equipment and medicines) of the states (and their citizens) in the fight against coronavirus.

\section{Literature Review}

A hospital aircraft has several medical resources, such as defibrillators, infusion pump, oxygen, stretcher, heart rate monitor, being prepared to treat patients with critical conditions, or who need to be transported under medical care. Thanks to the operation of 
this type of aircraft, humanitarian aid and air rescues have already saved millions of people throughout history. The use of a hospital plane to combat the pandemic allows shortening time and distance, presenting aid to health systems in several cities in the country.

In the current context of COVID-19, the aeromedical evacuation of patients is justified by the objective of transferring patients who need treatment in a center of greater complexity and technical technological experience, in addition to professionals specialized in the area of intensive care (Wanner et al., 2020).

Among the aircraft options manufactured by Embraer that can be changed to provide some type of aeromedical transport, this article analyzed the models: Phenom 100EV, Phenom 300E, Legacy 450, Legacy 500, Praetor 500 and Praetor 600, aiming to select the most suitable aircraft to be purchased by the Brazilian Government to be used in the fight against the pandemic of the new coronavirus.

\section{Hypotheses/Objectives}

Aiming to understand the problematic situation, this article applied a method of structuring widely used in decision problems, called Value-Focused Thinking (VFT) (Keeney, 1996), to define the objectives, alternatives, and criteria. After structuring the problem and consulting public health specialists, the authors concluded that the best strategy would be the use of a hospital aircraft, considering that this alternative meets all the objectives evaluated as relevant for the analysis.

Therefore, the article aims to select through AHP method (Saaty,1980) the most indicated aircraft to be acquired by the Brazilian Government to be used in aeromedical evacuation in the fight against COVID-19.

\section{Research Design/Methodology}

For the feasibility of the present study, three aircraft decision-makers/specialists were consulted, who evaluated the alternatives in the light of the established criteria, using the AHP method. Table 1 shows the criteria selected to make up the analysis.

Table 1 - Definition of criteria.

\begin{tabular}{|c|c|c|}
\hline \multicolumn{2}{|l|}{ Criterion } & Definition \\
\hline $\begin{array}{l}\text { Reach } \\
(\mathrm{Km})\end{array}$ & $\mathrm{C}_{1}$ & Maximum distance reached by the aircraft without refueling. \\
\hline $\begin{array}{l}\text { Length } \\
\text { (m) }\end{array}$ & $\mathrm{C}_{2}$ & $\begin{array}{l}\text { Distance from the bow to the stern of the aircraft, measured on the longitudinal } \\
\text { axis. }\end{array}$ \\
\hline $\begin{array}{l}\text { Distance from } \\
\text { Takeoff }(\mathrm{m})\end{array}$ & $\mathrm{C}_{3}$ & Required distance traveled on the ground before the aircraft takes flight. \\
\hline $\begin{array}{c}\text { Distance } \\
\text { landing }(\mathrm{m})\end{array}$ & $\mathrm{C}_{4}$ & Distance traveled on the ground of an aircraft that lands. \\
\hline $\begin{array}{c}\text { Ability } \\
\text { Luggage }\left(\mathrm{ft}^{3}\right)\end{array}$ & $\mathrm{C}_{5}$ & The volume available for transport of medicines and food for humanitarian aid. \\
\hline Number of patients & $\mathrm{C}_{6}$ & The maximum number of patients safely transported by the aircraft. \\
\hline Cruising speed $(\mathrm{Km} / \mathrm{h})$ & $\mathrm{C}_{7}$ & Speed at which, thanks to the low density of air, less fuel is used. \\
\hline $\begin{array}{l}\text { Length } \\
\text { of the cabin (ft) }\end{array}$ & $\mathrm{C}_{8}$ & Useful cabin length, which could be used to carry medicines or passengers. \\
\hline $\begin{array}{c}\text { Cost } \\
(\mathrm{U} \$ \$ \mathrm{Mi})\end{array}$ & $\mathrm{C}_{9}$ & The estimated cost of aircraft acquisition. \\
\hline
\end{tabular}


ISAHP Article: A Style Guide for Individual Papers To Be Submitted to the International Symposium of the Analytic Hierarchy Process 2020, Web Conference.

To make up the set of alternatives, six models of aircraft manufactured by Embraer were selected, which can be changed to provide some type of aeromedical transport: Phenom 100EV, Phenom 300E, Legacy 450, Legacy 500, Praetor 500 and Praetor 600.

\section{Data/Model Analysis}

In order to assist in the evaluation of the alternatives by the specialists, table 2 was presented to them, with the operational and hospital characteristics of each aircraft.

Table 2 - Aircraft characteristics.

\begin{tabular}{|c|c|c|c|c|c|c|c|c|c|}
\hline Plane & $\mathrm{C}_{1}$ & $\mathrm{C}_{2}$ & $\mathrm{C}_{3}$ & $\mathrm{C}_{4}$ & $\mathrm{C}_{5}$ & $\mathrm{C}_{6}$ & $\mathrm{C}_{7}$ & $\mathrm{C}_{8}$ & $\mathrm{C}_{9}$ \\
\hline $\begin{array}{c}\text { Phenom } \\
100 \text { EV }\end{array}$ & 2182 & 12,82 & 975 & 740 & 70 & 7 & 750 & 11 & 4,81 \\
\hline $\begin{array}{c}\text { Phenom } \\
300 \mathrm{E}\end{array}$ & 3722,52 & 15,84 & 962,7 & 675 & 84 & 10 & 859 & 17 & 10,6 \\
\hline $\begin{array}{c}\text { Legacy } \\
450\end{array}$ & 5378 & 19,68 & 1191 & 637 & 150 & 9 & 855 & 24 & 18,44 \\
\hline $\begin{array}{c}\text { Legacy } \\
500\end{array}$ & 5788 & 20,74 & 1245 & 647 & 155 & 12 & 864 & 27,6 & 22,25 \\
\hline $\begin{array}{c}\text { Praetor } \\
500\end{array}$ & 6186 & 19,68 & 867 & 636 & 150 & 9 & 862 & 24 & 18,9 \\
\hline $\begin{array}{c}\text { Praetor } \\
600\end{array}$ & 6888 & 20,74 & 1438 & 660 & 155 & 12 & 863 & 27,6 & 23,3 \\
\hline
\end{tabular}

After the application of the AHP method, the classification of the alternatives was obtained, according to Table 3 .

Table 3 - Classification of the alternatives.

\begin{tabular}{cc}
\hline Alternative & Ranking \\
\hline Legacy 450 & 1 \\
Praetor 500 & 2 \\
Phenom 100EV & 3 \\
Phenom 300E & 4 \\
Legacy 500 & 5 \\
600 Praetor & 6 \\
\hline
\end{tabular}

\section{Limitations}

The main limitation of this study lies in that our analysis was conducted using only data available on EMBRAER's official pages, which made it impossible to access some criteria that would be important for the proposed analysis, especially characteristics related to the hospital capacity of the aircrafts.

\section{Conclusions}

In view of the above, the objective of this article was achieved, with the choice of the Legacy 450 aircraft to be acquired and used in aeromedical evacuations in the fight against the pandemic of the new coronavirus. It is noteworthy that, even with the cooling of the pandemic, which should occur after the discovery and availability of a vaccine, the acquired hospital aircraft could continue to be used in humanitarian aid to poorer countries and in situations of critically ill patients requiring aeromedical evacuation to regions with higher hospital capacity.

It is emphasized that the AHP method proved to be efficient for the proposed analysis, enabling the evaluation of specialists, both in obtaining the weights of the criteria and in the evaluation of alternatives, which makes the decision-making process more transparent and reliable. 
ISAHP Article: A Style Guide for Individual Papers To Be Submitted to the International Symposium of the Analytic Hierarchy Process 2020, Web Conference.

\section{Key References}

Gutiérrez-Aguilar, R., Cordoba-Lepe, F., Muñoz-Quezada, M. T., \& Gutiérrez-Jara, J. P. (2020). Model for a threshold of daily rate reduction of COVID-19 cases to avoid hospital collapse in Chile. Medwave, 20(3), e7871. https://doi.org/10.5867/medwave.2020.03.7871

Keeney, R. L. (1996). Value-Focused Thinking. Harvard University Press.

Saaty, T. L. The Analytic Hierarchy Process. Mcgraw-Hill, New York, 1980.

Wanner, E. M., Gino La Rosa, A., María Carolina Cabrera, S., Carlos Polanco, L., \& Xabier De Aretxabala, U. (2020). Case reports: Aeromedical evacuation of patients COVID-19. Chilean Anesthesia Journal ,49(3), 416-424. https://doi.org/10.25237/REVCHILANESTV49N03.021. 